\title{
Variation in Platycladus orientalis (Cupressaceae) Reproductive Output and Its Effect on Seed Orchard Crops' Genetic Diversity
}

\author{
Si-Qian Jiao ${ }^{1}$, Meiyu Li ${ }^{1}$, Yuan-Jiao Zhu ${ }^{2}$, Shan-Shan Zhou ${ }^{1}$, Shi-Wei Zhao ${ }^{1}$, Zhi-Chao Li ${ }^{1}$, Yu-Tao Bao ${ }^{1}$, \\ Tian-Le Shi ${ }^{1}$, Hui-Jin Zhang ${ }^{3}$, Xiao-Lei Yang ${ }^{3}$, Ji-Jun Zhu ${ }^{3}$, Ilga Porth ${ }^{4}$, Yousry A. El-Kassaby ${ }^{5}{ }^{(}$, \\ Shi-Ping Cheng ${ }^{6}{ }^{\mathbb{D}}$, Yue $\mathrm{Li}^{1}$ and Jian-Feng Mao ${ }^{1, *(1)}$
}

check for updates

Citation: Jiao, S.-Q.; Li, M.; Zhu, Y.-J.; Zhou, S.-S.; Zhao, S.-W.; Li, Z.-C.; Bao, Y.-T.; Shi, T.-L.; Zhang, H.-J.; Yang, X.-L.; et al. Variation in Platycladus orientalis (Cupressaceae) Reproductive Output and Its Effect on Seed Orchard Crops' Genetic Diversity. Forests 2021, 12, 1429. https://doi.org/10.3390/f12111429

Academic Editors: Álvaro Soto and Pablo G. Goicoechea

Received: 4 September 2021

Accepted: 15 October 2021

Published: 20 October 2021

Publisher's Note: MDPI stays neutral with regard to jurisdictional claims in published maps and institutional affiliations.

Copyright: (c) 2021 by the authors. Licensee MDPI, Basel, Switzerland. This article is an open access article distributed under the terms and conditions of the Creative Commons Attribution (CC BY) license (https:// creativecommons.org/licenses/by/ $4.0 /)$.
1 Beijing Advanced Innovation Center for Tree Breeding by Molecular Design, National Engineering Laboratory for Tree Breeding, College of Biological Sciences and Technology, Beijing Forestry University, Beijing 100083, China; siqianjiao@bjfu.edu.cn (S.-Q.J.); meiyulily@163.com (M.L.); shanshan9@bjfu.edu.cn (S.-S.Z.); shwzhao997@bjfu.edu.cn (S.-W.Z.); zhichaoli@bjfu.edu.cn (Z.-C.L.); yutaobao@bjfu.edu.cn (Y.-T.B.); tianleshi@bjfu.edu.cn (T.-L.S.); liyue@bjfu.edu.cn (Y.L.)

2 School of Economics, Yunnan University, Kunming 650091, China; zyj15838023462@163.com

3 National Tree Breeding Station for Platycladus orientalis in Jiaxian, Forest Farm of Jiaxian County, Jiaxian 467100, China; zhang15837506876@163.com (H.-J.Z.); yangxiaolei137137@163.com (X.-L.Y.); jxlchyx@163.com (J.-J.Z.)

4 Département Des Sciences Du Bois Et De La Forêt, Pavillon Charles-Eugène-Marchand, 1030, Avenue De La Médecine, Université Laval, Québec, QC G1V 0A6, Canada; ilga.porth@sbf.ulaval.ca

5 Department of Forest and Conservation Sciences, Faculty of Forestry, University of British Columbia, Vancouver, BC V6T 1Z4, Canada; y.el-kassaby@ubc.ca

6 Henan Key Laboratory of Germplasm Innovation and Utilization of Eco-Economic Woody Plant, Pingdingshan University, Pingdingshan 467000, China; shipingcheng@163.com

* Correspondence: jianfeng.mao@bjfu.edu.cn; Tel.: +86-13366181735

Abstract: The genetic efficiency of seed orchards is crucial for determining seed crops' genetic gain and diversity. Platycladus orientalis is a conifer tree of important ecological value in China. Here, we assessed the reproductive output (fertility) variation for 166 clones in a first-generation P. orientalis seed orchard over five years and across three years for each gender (female: 2017, 2018, and 2020 and male: 2017, 2019, and 2021). Fertility variation and genetic diversity parameters were estimated for each gender-year combination. The reproductive output (fertility) variation differed among years, provinces, clones nested within provinces, and ramets within clones. We observed asymmetry in the gender reproductive output and parental imbalance and determined their profound effects on the genetic diversity of these seed crops. The maleness index revealed the existence of female-biased or male-biased clones. When seeds from multiple individuals and years were blended, we found an increase in the effective number of parents $\left(N_{p}\right)$ and in genetic diversity $(G D)$, and a reduced fertility variation $(\Psi)$ in the seed orchard. When we set the effective number of parents $\left(N_{p}\right)$ to 30 , the GD of the seed orchard could be maintained at more than $95 \%$. Thus, achieving genetic diversity balance in seed production can be accomplished through monitoring the fertility variation of orchards and through the utilization of the thereby generated information for the advanced generation of seed orchards.

Keywords: Platycladus orientalis; reproductive strobili production; fertility variation; effective parent number; parental balance

\section{Introduction}

The genetic efficiency of seed orchards (the degree to which seed crops reflect their parental population genetic superiority) is crucial, as it determines the degree of genetic gain and diversity for future forest tree plantations [1]. Parental gametic contribution is an important factor affecting the extent of the captured genetic gain in the seed orchard [2], while the effective population size of seed crops is an important indicator of their genetic 
diversity [3]. Platycladus orientalis (Linn.) Franco is an endemic evergreen, monoecious tree of the Cupressaceae distributed in Northern and Northwestern China, South Korea, and Russia. P. orientalis (common name: Oriental thuja) is known for its wide adaptability, and drought and cold tolerance, and has become an important ecological afforestation and restoration tree species in Northern China [4]. The wood of this species is characterized by its high density and decay-resistance, making it suitable for construction and furniture manufacturing. Additionally, the leaves, branches, and seeds of this species have great medicinal values [5], and P. orientalis is also common in landscaping. Due to these significant attributes, the planting volume of this species is ever increasing, and its position in forestry production is becoming more prominent [6].

In China, tree improvement and selective breeding activities of P. orientalis focusing on the phenotypic selection of growth attributes started in the 1980s, resulting in the establishment of provenance testing and seed orchards. The largest $P$. orientalis seed orchard was established in 1989 in Jiaxian County, Henan Province [7]. Currently, the reproductive output of this seed orchard has not been fully assessed, as seed production is unstable and the annual production is substantially varied [8].

A quantitative evaluation of the reproductive output in coniferous seed orchards and an estimation of fertility variation among individuals provide useful information for the management and effective utilization of their seed crops [9]. Fertility variation is defined as the difference in the ability of individuals to produce viable progeny (i.e., reproductive output) $[10,11]$. The most commonly used method for predicting or estimating parental reproductive output in forest tree seed orchards is counting the reproductive buds [12-14] or male and female strobili $[13,15]$. Quantifying fertility variation in seed orchard populations can help manage the genetic diversity and reduce the impact of fertility differences [16].

The genetic quality of clonal seed orchard crops has been a key step in conifer improvement programs, including P. orientalis. However, the genetic quality of the P. orientalis seed orchard has not been evaluated, but is assumed to be dependent on many factors, including reproductive output variation, reproductive phenology, mating system dynamics, and gene flow [17-19]. In a seed orchard, it is commonly observed that the reproductive output (male and female strobili production) of parents substantially varies, resulting in a small portion of the seed parents contributing a disproportionately large number of gametes to the progeny [20-22]. For example, the "20:80 rule" claims that $20 \%$ of the parents in an orchard will produce as much as $80 \%$ of the entire seed crop [23]. This unequal/distorted reproductive output contribution leads to a relatedness buildup and potential reduction of genetic diversity in orchard seed crops.

Effective population size $(\mathrm{Ne})$ is one of the key genetic indicators in plant breeding, conservation, and population genetics $[24,25])$ as it quantifies the magnitude of genetic drift and inbreeding in a real population $[9,16]$. However, as Ne is notoriously difficult to assess in practice and in the context of forestry, Kang [13] introduced a simplified method for assessing $\mathrm{Ne}$ using the sibling coefficient $(\Psi)$, which is the probability that two alleles randomly selected from the gamete gene pool originated from the same parent. In contrast, the effective number of parents in the $P$. orientalis first generation clonal seed orchard has not been reported, which would provide a useful tool for assessing the Ne for this seed orchard.

Here, we assessed the reproductive output of this P. orientalis first generation clonal seed orchard with the following objectives: (1) surveying female and male strobili production over multiple years, (2) estimating female and male fertility variation among individuals, (3) estimating the effective number of parents so as to monitor the genetic diversity of orchard seed crops over the study years, and (4) discussing effective seed crop management practices so the genetic diversity of seed crops are maximized. 


\section{Material and Methods}

\subsection{Platycladus orientalis Clonal Seed Orchard}

We studied a first-generation P. orientalis clonal seed orchard that was established in the 1980s (Jiaxian County, Henan Province, China $\left(33^{\circ} 48^{\prime} 00^{\prime \prime}-34^{\circ} 11^{\prime} 50^{\prime \prime}\right.$ N, $113^{\circ} 01^{\prime} 45^{\prime \prime}-$ $\left.113^{\circ} 24^{\prime} 50^{\prime \prime} \mathrm{E}\right)$ ). The orchard population consisted of 268 phenotypically selected parents (clones) selected from 24 provenances within the Henan Province representing the species central range [26]. The seed orchard covered 35 hectares (ha), and clones were randomly arranged in 13 plots over two blocks, with $2 \mathrm{~m}$ spacing between trees within rows and $6 \mathrm{~m}$ between rows [7]. The present study focused on one of the two blocks for its high survival, which contained 166 clones ( $N=5763$ ramets) growing in three plots. We monitored the orchard's reproductive output over five years (2017-2021) with three years for parental female $(2017,2018$, and 2020) and male $(2017,2019$, and 2021) output.

We estimated the reproductive output of female parents by counting the abundance of seed cones in all ramets within the studied block. Depending on the abundance of cones, the fertility of female clones was divided into 11 different grades (from 0: no cone, to 10: abundant cones), following Woods (2005) [27] (female gametic contribution, Method F1: visual assessment of seed cone yield of each ramet for all 166 clones during 2017, 2018, and 2020). The specific method was done by first visually observing the fertility level of the plant with the highest number of male flowers in the seed orchard as the tenth class, on the basis of which the fertility of the other plants was assigned to classes $0-10$.

We estimated the reproductive output of male parents by counting the abundance of male strobili for all ramets across the studied block, following Woods (2005) [27] (male fertility, method M3: visual assessment of the male strobili production of each ramet of all clones). In this method, the abundance of male strobili was again classified into 11 different grades (0: no strobilus, 10: abundant strobili). Counting of the male strobili was conducted for all 166 clones during the 2017, 2019, and 2021 pollen shedding periods. The grading score was in proportion to the quantities of both male and female strobili production, allowing for a direct comparison of male and female reproductive grading scores.

\subsection{Genetic Variation and Parental Balance}

Statistical summaries of the scores of individual male and female reproductive outputs across the studied years were calculated using the psych package in $R$ ( $R$ version 4.0.3; $R$ Foundation for Statistical Computing, Vienna, Austria) [28]. Analysis of variance (ANOVA) of reproductive outputs between genders, and the nested-ANOVA of male and female strobili production across years, provenances, and clones nested within provenances were conducted using SPSS Version 24.0 (SPSS 24.0; SPSS Inc., Chicago, IL, USA) [29]. Pearson's product moment and Spearman rank-order were used to analyze the correlation between female and male strobili production in the studied years.

Parental balance curves were used to characterize high- and low-yield male strobili and seed cone individuals, following Chaisurisri and El-Kassaby [30]. The genetic contributions of females and males can be explained by the parental balance curves, while cumulative percentage curves are often used to quantify fertility variation $[11,31]$.

The maleness index $(M i)$, defined as the proportion of a clone's reproductive output transmitted through its male strobili production [13], was estimated following [32], as follows:

$$
M i=\mathrm{m}_{\mathrm{i}} /\left(\mathrm{m}_{\mathrm{i}}+\mathrm{f}_{\mathrm{i}}\right)
$$

where $m_{i}$ and $f_{i}$ are the genetic contributions (or reproductive output) of male and female in the i-th clones, respectively.

\subsection{Estimation of Fertility Variation}

Parental fertility is defined as the proportion of gametic contribution from female and male parents to their progeny [31,33]. Fertility variation is described by the sibling coefficient $(\Psi)$, which is the probability that two alleles randomly selected from the gamete gene pool originated from the same parent [13]. Additionally, the sibling coefficient is related 
to the coefficient of variation $(\mathrm{CV})$ of the female and male reproductive outputs $[13,34]$. Thus, the parental fertility sibling-coefficient $(\Psi)$ can be further described separately as the female sibling coefficient $\left(\Psi_{f}\right)$ and male sibling coefficient $\left(\Psi_{m}\right)$. The coefficient of variation $(\mathrm{CV})$ of the female and male reproductive outputs was used to estimate the female and male fertility $\left(\Psi_{f}\right.$ and $\left.\Psi_{m}\right)$ among individuals [9], as follows:

$$
\begin{gathered}
\Psi_{f}=N \Sigma_{\mathrm{i}=1}^{N} f_{i}^{2}=C V_{f}^{2}+1 \\
\Psi_{m}=N \Sigma_{\mathrm{i}=1}^{N} m_{i}^{2}=C V_{m}^{2}+1
\end{gathered}
$$

where $N$ is the census number; fi and $\mathrm{mi}$ are the proportional contributions of female and male in the i-th individual, respectively; and $C V_{f}$ and $C V_{m}$ are the coefficients of variation of reproductive outputs of female and male parents among individuals in the studied population, respectively.

P. orientalis, as a monoecious species, may show a positive or negative correlation between male and female fertility. Under the covariation between female and male fertility, the variation of parental fertility $(\Psi)$ can be obtained by using the Person's correlation coefficient $(r)$ as follows:

$$
\Psi=0.25\left(\Psi_{f}+\Psi_{m}\right)+0.5 \mathrm{r} \sqrt{(\Psi f-1)(\Psi m-1)}
$$

where $\Psi_{f}$ and $\Psi_{m}$ are the sibling coefficients of female and male parents, respectively, and $\mathrm{r}$ is the Person's product-moment correlation coefficient between female and male reproductive outputs in the population [9].

\subsection{Estimation of Effective Number of Parents}

The effective number of female $\left(N_{p}{ }^{(f)}\right)$ and male $\left(N_{p}{ }^{(m)}\right)$ parents can be calculated from the female $\left(\Psi_{f}\right)$ and male $\left(\Psi_{m}\right)$ sibling coefficients, respectively. They are correlated with their respective coefficients of variation (female $C V_{f}$ and male $C V_{m}$ ) $[13,34]$ as follows:

$$
\begin{aligned}
& N_{P}^{(f)}=N / \Psi_{f}=N /\left(C V_{f}^{2}+1\right) \\
& N_{P}{ }^{(m)}=N / \Psi_{m}=N /\left(C V_{m}^{2}+1\right)
\end{aligned}
$$

where $N$ is the census number; $\Psi_{f}$ and $\Psi_{m}$ are the sibling coefficients of female and male, respectively; of the i-th individual, and $C V_{f}$ and $C V_{m}$ are the coefficients of variation of female and male reproductive outputs, respectively, in the studied population.

With the Person's correlation coefficient ( $r$ ) between female and male reproductive outputs, Formula (4) for the parental effective number of parents $\left(N_{P}\right)$ can further be developed with the correlation coefficient $(r)$ as follows:

$$
N_{P}=N / \Psi=4 N /\left[\left(\Psi_{f}-1\right)+\left(\Psi_{m}-1\right)+2 \mathrm{r} \sqrt{(\Psi f-1)(\Psi m-1)}+4\right]
$$

where $N$ is the census number; $\Psi$ is the sibling coefficient of parental; $\Psi_{f}$ and $\Psi_{m}$ are the sibling coefficients of female and male parents, respectively; $C V_{f}$ and $C V_{m}$ are the coefficients of variation of female and male reproductive outputs, respectively; and $r$ is the Pearson's correlation coefficient between female and male reproductive outputs.

\subsection{Assessment of Relative Effective Parent Size and Genetic Diversity}

The relative significant number $\left(N_{r}\right)$ of parents was calculated by dividing the relative proportion of the effective number of parents $\left(N_{P}\right)$ by the census number $(N)$, which describes the percentage of the real population as the ideal population [9]. It was estimated by the combination of female and male parents, as follows: 


$$
\begin{gathered}
N_{r}(\%)=N_{P} / N \times 100, \\
N_{r}^{(f)}(\%)=\left(N_{P}^{(f)}\right) / N \times 100, \\
N_{r}{ }^{(m)}(\%)=\left(N_{P}^{(m)}\right) / N \times 100
\end{gathered}
$$

The loss of genetic diversity (GD) between generations (from parents to offspring) was estimated following Nei [35], Lacy [36], and Lindgren and Mullin [37], as follows:

$$
\begin{aligned}
& \text { GD loss }(\%)=0.5 / N_{p} \times 100 \\
& \text { GD }(\%)=1-\text { GD loss }(\%)
\end{aligned}
$$

\section{Results}

\subsection{Female and Male Reproductive Output}

Female and male strobili abundance varied substantially and significantly $(p<0.001)$ among years, provenances, and clones nested within provinces (Tables 1 and 2, and Supplementary Table S1). Across the three studied years, the clonal seed- and pollen-cone mean output was 2.775 and 4.208 , respectively (Table 2). Additionally, substantial variation was observed among the seed-cone (mean: 2.767; range: 1.667-4.778) and pollen-cone (mean: 4.177; range: 2.000-5.000) (Supplementary Table S1). It should be highlighted that in addition to the reproductive output variation observed among years, clones, and provenances,

\begin{tabular}{|c|c|c|c|c|c|c|}
\hline Character & SOV & Df & Sum Sq & Mean Sq & F Value & $\operatorname{Pr}(>F)$ \\
\hline \multirow{6}{*}{ Female } & Year & 2 & 3567 & 1783.6 & 806.368 & $<2 \times 10^{-16 * * *}$ \\
\hline & Provenance & 11 & 165 & 15 & 6.77 & $1.83 \times 10^{-11 * * *}$ \\
\hline & Year * Provenance & 22 & 107 & 4.9 & 2.204 & $0.000948^{* * *}$ \\
\hline & Year * Provenance (Clone) & 308 & 835 & 2.7 & 1.226 & $0.004511^{* *}$ \\
\hline & Provenance (Clone) & 154 & 707 & 4.588 & 1.875 & $1.83 \times 10^{-10 * * *}$ \\
\hline & Residuals & 15,696 & 34,718 & 2.2 & & \\
\hline \multirow{6}{*}{ Male } & Year & 2 & 1670 & 835 & 259.166 & $<2 \times 10^{-16 * * *}$ \\
\hline & Provenance & 11 & 83 & 7.6 & 2.346 & $0.00697^{* *}$ \\
\hline & Year *Provenance & 22 & 251 & 11.4 & 3.543 & $3.70 \times 10^{-8 * * *}$ \\
\hline & Year * Provenance (Clone) & 308 & 783 & 2.5 & 0.789 & 0.99726 \\
\hline & Provenance (Clone) & 154 & 875 & 5.682 & 1.709 & $3.70 \times 10^{-7 * * *}$ \\
\hline & Residuals & 15,696 & 50,573 & 3.2 & & \\
\hline
\end{tabular}
within the clone, the reproductive output also varied and this variation was substantiated by the observed high gender and year $C V(>30 \%)$ values (Supplementary Figures S1-S3, Supplementary Tables S2 and S3).

Table 1. ANOVA of P. orientalis female and male strobili production across years, provenance, and clones.

${ }^{*}$ represents the interaction between two sources of variation. ${ }^{* *} p<0.01 ;{ }^{* * *} p<0.001$.

Table 2. Summary statistics (mean (M), standard deviation (SD), median, range, and standard error (SE)) of $P$. orientalis male and female strobili production across years ( $N=5763$ individuals).

\begin{tabular}{ccccccc}
\hline Characters & Years & Mean & SD & Median & Range & SE \\
\hline \multirow{5}{*}{ Male } & 2017 & 3.858 & 1.831 & 4 & $0-10$ & 0.024 \\
& 2019 & 4.159 & 1.451 & 4 & $0-8$ & 0.019 \\
& 2021 & 4.626 & 2.081 & 5 & $0-10$ & 0.027 \\
& Total & 4.208 & 1.830 & 4 & $0-10$ & 0.014 \\
\multirow{5}{*}{ Female } & 2017 & 2.474 & 1.454 & 2 & $0-8$ & 0.019 \\
& 2018 & 3.437 & 1.601 & 3 & $0-10$ & 0.021 \\
& 2020 & 2.383 & 1.441 & 2 & $0-10$ & 0.019 \\
& Total & 2.775 & 1.574 & 3 & $0-10$ & 0.0124 \\
\hline
\end{tabular}




\subsection{Reproductive Output Parental Balance}

The nested-ANOVA revealed significant differences $(p<0.001)$ among years, provenances, and clones nested within provenances, (Table 1), and the scores of the male reproductive output were always higher than those for the female reproductive output (Table 2, Supplementary Table S1, and Supplementary Figure S1). The gender analyses revealed the presence of highly significant $(p<0.001)$ differences between the scores of male and female reproductive outputs (Table 3 ).

Table 3. ANOVA of P. orientalis strobili (seed cones and pollen cones) production.

\begin{tabular}{cccccc}
\hline SOV & Df & Sum Sq & Mean Sq & F Value & $\operatorname{Pr}(>\mathbf{F})$ \\
\hline Gender & 1 & 5540 & 5540 & 3937 & $<2 \times 10^{-16 * * *}$ \\
Residuals & 10,794 & 15,189 & 1 & & \\
\hline *** & & & & &
\end{tabular}

$\overline{* * *} p<0.001$.

The Spearman's rank correlation coefficients between years of female and male reproduction outputs were positive and significant (Tables 4 and 5). Simultaneously, for 2017, the year with male and female reproduction output data, the correlations were positive and significant (Table 6). Furthermore, the maleness index results showed female-biased (high female gamete production but low male gamete production) or male-biased (high male gamete production but low female gamete production) in a few clones (Figure 1). Seven clones indicated that the paternal contribution was greater than the maternal one. The genetic and reproductive maleness index of these seven clones were $\geq 0.60$ (clones \# 238, 51 , 87, 111, 248, 242, and 99 (Figure 1 and Supplementary Table S4)). In contrast, eight clones showed a greater maternal than paternal contribution in 2017, with a maleness index $\leq 0.48$ (clones \# 71, 178, 147, 163, 179, 241, 188, and 78 (Figure 1 and Supplementary Table S4)).

Table 4. The Spearman's rank correlation coefficient of female strobilus productions between years based on pooling of families.

\begin{tabular}{|c|c|c|c|}
\hline Female & 2017 & 2018 & 2020 \\
\hline 2017 & & $0.264^{* *}$ & $0.259^{* *}$ \\
\hline 2018 & & & $0.177^{* *}$ \\
\hline 2020 & & & \\
\hline
\end{tabular}

Table 5. The Spearman's rank correlation coefficient of male strobilus productions between years based on pooling of families.

\begin{tabular}{cccc}
\hline Male & 2017 & 2019 & 2021 \\
\hline 2017 & & $0.325^{* * *}$ & $0.328^{* *}$ \\
2019 & & & $0.222^{* *}$ \\
2021 & & & \\
\hline
\end{tabular}

** At the $p$ value $<0.01$, indicates significant correlation.

Table 6. The Spearman's rank correlation coefficient of female and male strobilus productions 2017.

\begin{tabular}{|c|c|c|}
\hline & 2017 Male & 2017 Female \\
\hline $\begin{array}{l}2017 \text { Male } \\
2017 \text { Female }\end{array}$ & & 0.098 ** \\
\hline
\end{tabular}

** At the $p$ value $<0.01$, indicates significant correlation. 


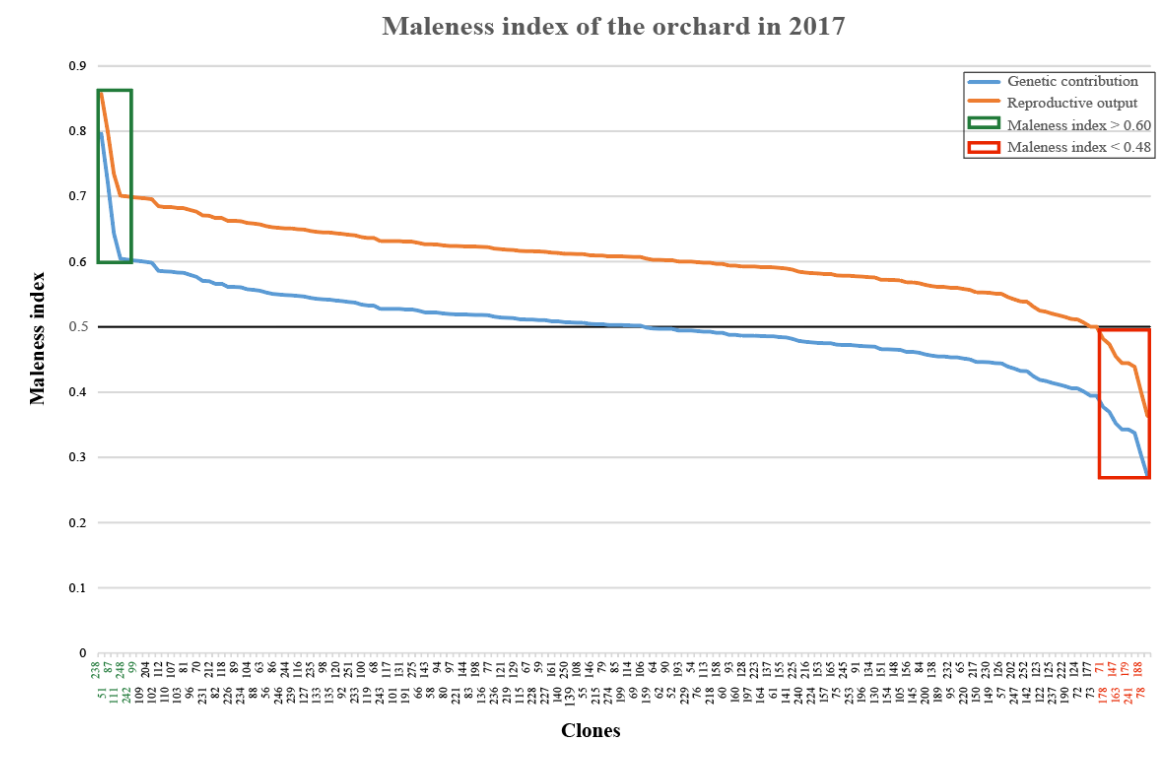

Figure 1. The 2017 clone maleness index.

The parental balance curves showed a slight fluctuation in the production of male strobili and female-cone among the years, and the clonal cumulative gamete contribution deviated from an equal contribution (Figure 2). These results indicated that male and female parents contributed unequally to the gamete gene pool. Thus, specific individuals may consistently produce high or low numbers of seed- or pollen-cones (Tables 4 and 5). The cumulative curves of female cone production were significantly more distorted than that of the male strobili production (Figure 2). The top $20 \%$ of clones contributed $41 \%$ of the female strobili production (2020) and 33\% of the male production (2017). Similar trends were observed across the study years for male and female strobili production (Figure 2).
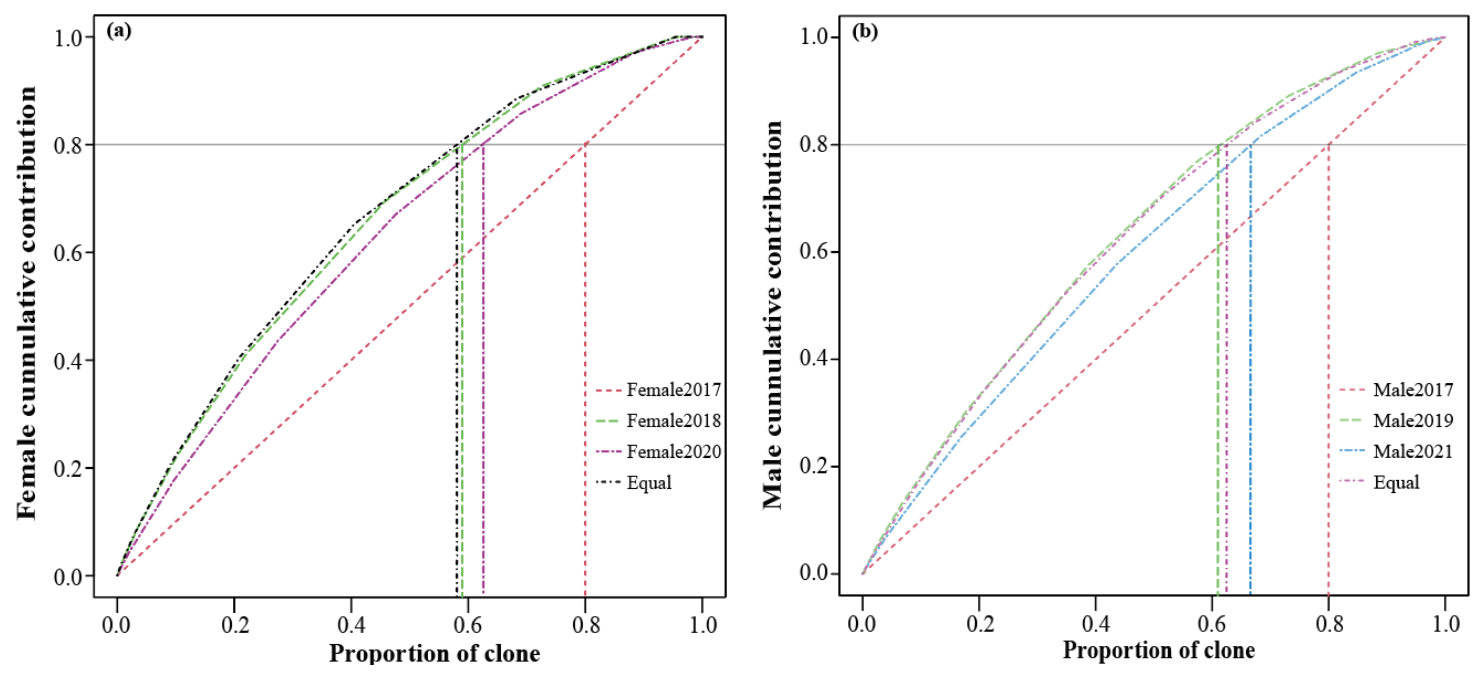

Figure 2. Female (a) and male (b) P. orientalis clonal cumulative contribution curves across years.

\subsection{Fertility Variation, Effective Population Size, and Genetic Diversity}

Fertility variation of male and female parents varied slightly among years (Table 1). Fertility variation ( $\Psi$ ) ranged from 1.112 (2019) to 1.223 (2017) for males $\left(\Psi_{m}\right)$ with little interannual variation, and with a similar trend observed for females $\left(\Psi_{f}\right)$ ranging from 1.215 (2017) to 1.367 (2020) (Table 7). When pooled across all clones and years, the fertility variation ( $\Psi)$ ranged from 1.100 to 1.654 , suggesting that fertility variation increased compared with that of the single year (Supplementary Tables S2 and S3). 
Table 7. Coefficient of variation $(C V)$, sibling coefficient $(\psi)$, effective number of parents $\left(N_{p}\right)$, relative effective number of parents $\left(N_{r}\right)$, and genetic diversity $(G D)$ for P. orientalis female and male strobili production $(N=166$ clones $)$.

\begin{tabular}{ccccccccc}
\hline \multirow{2}{*}{ Statistic } & \multicolumn{2}{c}{$\mathbf{2 0 1 7}$} & $\mathbf{2 0 1 8}$ & $\mathbf{2 0 1 9}$ & $\mathbf{2 0 2 0}$ & $\mathbf{2 0 2 1}$ & \multicolumn{2}{c}{ Pooled } \\
\cline { 2 - 9 } & Female & Male & Female & Male & Female & Male & Female & Male \\
\hline$C V$ & 0.584 & 0.472 & 0.464 & 0.349 & 0.606 & 0.451 & 0.567 & 0.435 \\
$\psi$ & 1.341 & 1.223 & 1.215 & 1.122 & 1.367 & 1.203 & 1.321 & 1.189 \\
$N$ & 166.0 & 166.0 & 166.0 & 166.0 & 166.0 & 166.0 & 166.0 & 166.0 \\
$N p$ & 123.8 & 135.8 & 136.6 & 148.0 & 121.4 & 137.9 & 125.6 & 139.6 \\
$N_{r}$ & 0.746 & 0.818 & 0.823 & 0.891 & 0.731 & 0.831 & 0.757 & 0.841 \\
$G D$ & 0.012 & 0.011 & 0.011 & 0.010 & 0.013 & 0.011 & 0.012 & 0.011 \\
loss\% & 0.988 & 0.989 & 0.989 & 0.990 & 0.987 & 0.989 & 0.988 & 0.989 \\
$G D$ & & & & & & &
\end{tabular}

The effective number of parents $\left(N_{p}\right)$ ranged from $121.4\left(N_{p}{ }^{f}: 2020\right)$ to $148.0\left(N_{p}{ }^{m}\right.$ : 2019) across the studied years (Table 7). The relative effective number of female parents $\left(N_{r}\right)$ varied between 0.731 (2020) and $0.823(2018)$, and that of male parents ranged between 0.818 (2017) and 0.891 (2019) (Table 7), where $N_{r}$ was calculated using the $N_{p}$ and $N$ of the female and male strobili production. The loss of genetic diversity (GD loss $\%$ ) in seed crops varied between 0.010 (2019) and 0.011 (2017 and 2021) for males and between 0.011 (2018) and 0.013 (2020) for females (Table 7).

The genetic diversity $(G D)$ extended from parents to offspring is closely related to the effective number of parents in the orchard (Figure 2). The genetic diversity (GD) estimates for new seed orchards' establishment were calculated using Equation (10). The genetic diversity $(G D)$ will be higher as we selected for a higher effective number of parents, but the larger the $N_{p}$, the slower the growth of GD (Figure 3). When we set the effective number of parents $\left(N_{p}\right)$ to 30 , the GD of the seed orchard could be maintained at more than $95 \%$ (Figure 3). If we tolerate a $10 \%$ loss of genetic diversity, we only need to retain an effective parentage of 5 to maximize genetic gain, while maintaining a certain level of genetic diversity for new seed orchards (Figure 3). A higher fertility variation led to a lower effective number of parents $\left(N_{p}\right)$, which in turn led to a less relative effective number of parents and resulted in an increase of genetic diversity loss (Table 7).

1.2

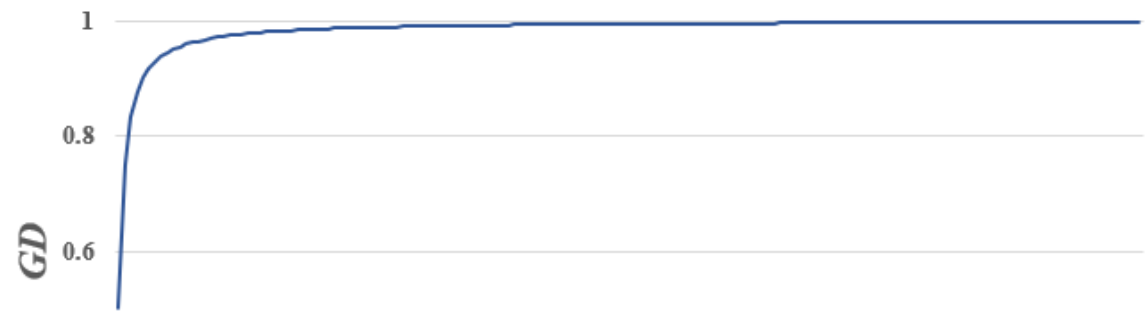

0.4

0.2

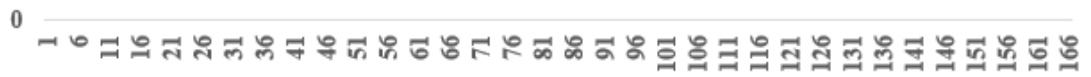

$N_{p}$

Figure 3. Relationship between effective number of parents $\left(N_{p}\right)$ and gene diversity $(G D)$ in the $P$. orientalis clonal seed orchard. 


\section{Discussion}

\subsection{Female and Male Strobili Production Variation}

The variation of gender and reproductive outputs in the parental populations of the seed orchards is expected to influence the genetic composition of the (resultant) seed crops. Generally, and notwithstanding the observed significant difference between genders, reproductive strobili production and their coefficient of variations $(\mathrm{CV})$ showed a tight association between female and male fertility (Table 1, Table 2, and Table 4), suggesting a gender reproductive output symmetry. This general pattern is different from previous studies which demonstrated gender asymmetry in the reproductive success of males and females in conifer seed orchards [20,38-40]. Reproductive output symmetry is influenced directly or indirectly by reproductive climatology [41], reproductive synchrony [2], and climatic factors during the formation of the reproductive primordia, such as precipitation and temperature [41].

Sexual asymmetry is common among monoecious plants [42]. However, the presence of hermaphroditic asymmetry may be beneficial for reducing the probability of selfing [43]. The maleness index provides a quantitative measure of gender. Clones with a high maleness index will have a relatively higher paternal than maternal contribution. So, we still found a limited number of clones displayed a distinct female (eight clones) or male (seven clones) tendency reflected in their genetic and reproductive maleness in 2017 (Figure 1 and Supplementary Table S4).

Significant positive and/or negative correlations between individual tree male and female strobili production are commonly observed. For example, positive correlations have been reported for Pinus taeda [44], Pinus nigra [45], and Picea abies [46], and negative correlations for Pinus nigra [38], Pinus elliottii [47], Pinus sylvestris [48], and Pinus contorta [49], as in the present study.

The positive correlation between the scores of male and female reproductive outputs increase fertility variation $(\Psi)$ and decrease the number of effective parents $\left(N_{p}\right)$ (Table 3). However, the negative correlation between the male and female reproductive output could mitigate the asymmetrical variation between $\Psi_{f}$ and $\Psi_{m}$ and reduce total fertility variation [50].

The reproductive output and coefficient of variation (CV) differed among years, clones nested within provinces, and individuals within clones (Tables 1 and 2). Similar parental reproductive output variations have been widely found among individuals and years within several seed orchards [10,16,51-53] and natural populations [54]. Our results show that the variation of male and female reproductive output between individuals and among years could be reduced when the total strobili production is completely pooled. Thus, mixing seed crops from several years could be beneficial to reduce the reproductive output difference and fertility variation if the demand on the seed is not high [16].

\subsection{Fertility Variation and Effective Number of Parents}

The genetic worth of orchards' seed crops is a function of parental gametic contribution and their respective breeding value; thus, fertility variation is an important criterion for assessing their genetic composition [13]. A large variation among the parental gametic contribution of seed orchards is common and widely reported [18]. The production of seed cones, pollen strobili, and seeds has been used to estimate fertility variation among individuals in many plant species $[48,55]$. The variations in female and male fertility were similar to the differences in the reproductive yield and $C V$ (Tables 1 and 2), and mixed seeds resulted in a decrease of female $\left(\Psi_{f}\right)$ and male $\left(\Psi_{m}\right)$ gametic fertility variations (Table 3$)$, and in an increase of the effective number of parents $\left(N_{p}\right)$ and genetic diversity $(G D)$ (Table 7), indicating that mixing seeds from both several clones and years could increase the genetic diversity of the seed lots.

The sibling coefficient $(\Psi)$ demonstrated that female fertility was relatively higher than the male counterpart (Table 2). It has previously been reported that a greater proportion of seed cones either abort or fail to produce viable seeds. This could be due to lack of 
fertilization [3], as was observed in a natural stand of teak and Acacia leucophloea $[3,56]$. Additionally, excessive reproduction from a reduced set of parents can lead to increased offspring relatedness, leading to greater erosion of genetic diversity [57]. Thus, greater care needs to be dedicated to monitoring parental fertility differences.

The genetic gain and genetic diversity of future forest tree populations are important indicators of the genetic worth of seed orchards. The obsessive pursuit of the highest genetic gain would lead to the genetic base of seed crops becoming too limited and the resulting forest stands would lack resilience to unpredictable environmental changes [1]. In seed orchards, the number of parents is an urgent issue to be addressed. The effective number of parents $\left(N_{p}\right)$ is used to estimate the genetic diversity in real populations [9]. As the number of effective parents increases, it may lead to an increase in breeding variation and genetic diversity, but also to a decrease in genetic gain (Figure 3 and Table 7). Genetic drift (pollen contamination) increases $N_{p}$ and $G D$, but at the same time leads to a reduced genetic worth of seed orchard crops [37]. However, it is the optimal choice to balance genetic diversity and genetic gain through the option of mixing/bulking multiple seed crops, supporting the same conclusions as for seed orchards of other species $[9,16,52]$. The obtained results from our study showed that genetic diversity of the parental population could be covered and saturated by collecting seeds from at least 30 mother trees, consistently with results reported for other species [58-60].

\subsection{Implications for Seed Orchard Management}

The success of an orchard seed production program is measured by the frequent and abundant delivery of viable seeds. Along with environmental conditions, the final seed yields of orchards are affected by several biological factors including pollination; fertilization; and embryo, seed, and cone development, and also by the genetic variation of clones. Evaluating the outcome of seed orchards requires assessing and predicting fertility variation; however, the present study is the first that addressed the observed fertility variation and generated information in P. orientalis seed orchard, as previous studies did not use this information to improve the seed crop quality of an orchard, resulting in missed opportunities. The seed crops of orchards must reflect the parental population genetic diversity and the allelic frequencies of target traits to maintain sufficient genetic diversity in the regenerated future forests and the successful capture of genetic gain. Fertility variation studies of orchards paved the way for the introduction of effective seed crop management to effectively reduce potential genetic diversity losses. These include individual parent/clone seed-cone harvest and seed extraction, so that the parental contribution of orchards can be effectively managed through the creation of "designer" seed crops composed of desired parental seed proportions $[10,61]$. Controlling the number of effective parents can also be used in seed orchard management to maintain a certain level of genetic diversity and improve the genetic gain as much as possible. Additionally, where possible, mixing seeds for several years may help enhance crops genetic diversity $[22,40,62,63]$.

\section{Conclusions}

Here, we used reproductive strobili production variation $(C V)$, fertility variation $(\Psi)$, and effective number of parents $\left(N_{p}\right)$ as tools to determine the genetic diversity and quality of $P$. orientalis seed orchard crops. The results highlight the existence of fertility differences between years, clones nested within provinces, gender, and unbalanced parental output, leading to a potential loss of genetic diversity, and offer opportunities for upgrading their genetic quality through proactive seed crop management activities. When the effective number of parents $\left(N_{p}\right)$ was increased, the genetic diversity $(G D)$ increased, while the fertility variation $(\Psi)$ and genetic gain decreased in the seed orchard. The creation of "designer" crops by mixing seeds from individual parents or, where possible, combining seed crops from different years and clones, was found to be the optimal choice to balance the genetic diversity and genetic gain. Indeed, when we set the effective number of parents $\left(N_{p}\right)$ to 30 , the GD of the seed orchard could be maintained at more than $95 \%$. Finally, achieving 
genetic diversity balance in seed production can be accomplished through monitoring fertility variation in orchards and through the utilization of the generated information for upgrading seed crops.

Supplementary Materials: The following are available online at https: / www.mdpi.com/article / $10.3390 / \mathrm{f} 12111429 / \mathrm{s} 1$, Table S1. Statistics of male and female reproductive output in different clones. Table S2. Coefficient of variation $\left(C V_{f}\right)$ and sibling coefficient $\left(\Psi_{f}\right)$ for female cones production in the P. orientalis clonal seed orchard $(N=5398)$. Table S3. Coefficient of variation $(\mathrm{CVm})$ and sibling coefficient $(\Psi m)$ for male strobili production in the P. orientalis clonal seed orchard $(N=5398)$. Table S4. Maleness index of 166 clones in 2017. Figure S1. Coefficient of variation (CV) of female and male strobili productions for different years in the P. orientalis clonal seed orchard. Different colors of labels correspond to different provenances. Figure S2. The mean value of female and male strobili productions for different years in the P. orientalis clonal seed orchard. Figure S3. The median value of female and male strobili productions for different years in the P. orientalis clonal seed orchard.

Author Contributions: J.-F.M. and Y.L. conceived and designed the experiments; S.-Q.J., M.L., T.-L.S., Z.-C.L. and Y.-T.B. conducted fieldwork; S.-P.C., Y.-J.Z., H.-J.Z., J.-J.Z. and X.-L.Y. collected the data; S.-Q.J., S.-W.Z. and S.-S.Z. analyzed the data; S.-Q.J. and J.-F.M. wrote the manuscript; Y.A.E.-K. and I.P. provided guidance and edited the manuscript. All authors have read and agreed to the published version of the manuscript.

Funding: This study was supported by grants from the National Natural Science Foundation of China (no. 31670664) and the Fundamental Research Funds for the Central Universities (no. 2018BLCB08).

Conflicts of Interest: The authors declare no conflict of interest.

\section{References}

1. Funda, T.; El-Kassaby, Y.A. CAB Reviews: Perspectives in Agriculture, Veterinary Science. Nutrition and Natural Resources. 2012. Available online: https:/ /www.researchgate.net/publication/235765316_Seed_orchard_genetics (accessed on 2 September 2021).

2. Li, W.; Wang, X.-R.; Li, Y. Stability in and correlation between factors influencing genetic quality of seed lots in seed orchard of Pinus tabuliformis Carr. over a 12-year span. PLoS ONE 2011, 6, e23544. [CrossRef]

3. Mutharaian, V.N.; Kamalakannan, R.; Narmatha Bai, V.; Mayavel, A.; Kim, D.Y.; Kang, K.-S. Fertility variation among individuals in natural stands of Acacia leucophloea. Silvae Genet. 2016, 65, 20-30. [CrossRef]

4. Hashemi, S.M.; Safavi, S.A. Chemical constituents and toxicity of essential oils of oriental arborvitae, Platycladus orientalis (L.) Franco, against three stored-product beetles. Chil. J. Agric. Res. 2012, 72, 188-194. [CrossRef]

5. Liu, B.; Wei, Y.; Li, G.; Chang, G.; Zhang, H. Advances in Medicinal Studies of Platycladus. In Proceedings of the 9th Annual Conference of Chemistry of Chinese Materia Medica, Xiamen, China, 8-9 November 2014.

6. Dong, T.; Chen, X.; Zhang, X. Platycladus orientalis, 1st ed.; Henan Science and Technology Press: Zhengzhou, China, 1990.

7. Huang, L.-S.; Song, J.; Sun, Y.-Q.; Gao, Q.; Jiao, S.-Q.; Zhou, S.-S.; Jin, Y.; Yang, X.-L.; Zhu, J.-J.; Gao, F.-L. Pollination dynamics in a Platycladus orientalis seed orchard as revealed by partial pedigree reconstruction. Can. J. Res. 2018, 48, 952-957. [CrossRef]

8. Huang, L.-S. Genetic Analysis of Pollination Dynamics in Platycladus orientalis Seed Orchard. Master's Thesis, Beijing Forestry University, Beijing, China, 2018.

9. Park, J.-M.; Kang, H.-I.; Yeom, D.-B.; Kang, K.-S.; El-Kassaby, Y.A.; Lee, K.-M. Gender, reproductive output covariation and their role on gene diversity of Pinus koraiensis seed orchard crops. BMC Plant Biol. 2020, 20, 418. [CrossRef]

10. Bila, A.D. Fertility Variation and Its Effects on Gene Diversity in Forest Tree Populations. Ph.D. Thesis, Swedish University of Agricultural Sciences, Umeå, Sweden, 2000.

11. Kang, K.-S. Genetic Gain and Gene Diversity of Seed Orchard Crops. Ph.D. Thesis, Swedish University of Agricultural Sciences, Uppsala, Sweden, 2001.

12. Grosser, C.; Potts, B.; Vaillancourt, R. Microsatellite based paternity analysis in a clonal Eucalyptus nitens seed orchard. Silvae Genet. 2010, 59, 57-62. [CrossRef]

13. Kang, K.-S. Clonal and annual variation of flower production and composition of gamete gene pool in a clonal seed orchard of Pinus densiflora. Can. J. Res. 2000, 30, 1275-1280. [CrossRef]

14. Philipson, J.J. Predicting cone crop potential in conifers by assessment of developing cone buds and cones. For. Int. J. For. Res. 1997, 70, 87-96. [CrossRef]

15. Muona, O.; Harju, A. Effective population sizes, genetic variability, and mating system in natural stands and seed orchards of Pinus sylvestris. Silvae Genet. 1989, 38, 221-228.

16. Bilir, N.; Kang, K.-S. Fertility variation, seed collection and gene diversity in natural stands of Taurus cedar (Cedrus libani). Eur. J. For. Res. 2020, 140, 199-208. [CrossRef]

17. Bilir, N. Fertility variation in wild rose (Rosa canina) over habitat classes. Int. J. Agric. Biol. 2011, 13, 110-114. 
18. Funda, T.; El-Kassaby, Y.A. Parental reproductive investment and success in conifer seed orchards. In Proceedings of the Seed Orchards and Breeding Theory Conference, Turkey, Japan, 21-25 May 2012; pp. 35-39.

19. Müller-Starck, G.; Ziehe, M. Reproductive systems in conifer seed orchards. Theor. Appl. Genet. 1984, 69, 173-177. [CrossRef]

20. El-Kassaby, Y.A.; Cook, C. Female reproductive energy and reproductive success in a Douglas-fir seed orchard and its impact on genetic diversity. Silvae Genet. 1994, 43, 243-246.

21. El-Kassaby, Y.A.; Fashler, A.M.K.; Crown, M. Variation in fruitfulness in a Douglas-fir seed orchard and its effect on cropmanagement decisions. Silvae Genet. 1989, 38, 113-121.

22. El-Kassaby, Y.A.; Reynolds, S. Reproductive phenology, parental balance, and supplemental mass pollination in a Sitka-spruce seed-orchard. Ecol. Manag. 1990, 31, 45-54. [CrossRef]

23. Anonymous. Twentieth Annual Report on Cooperative Tree Improvement and Hardwood Research Program; North Carolina State University: Raleigh, NC, USA, 1976.

24. Allendorf, F.W.; Luikart, G. Conservation and the Genetics of Populations, 1st ed.; Blackwell Publishing: Malden, MA, USA, 2007.

25. Frankham, R.; Ballou, S.E.J.D.; Briscoe, D.A.; Ballou, J.D. Introduction to Conservation Genetics, 1st ed.; Cambridge University Press: Cambridge, UK, 2002.

26. Jin, Y.; Ma, Y.; Wang, S.; Hu, X.-G.; Huang, L.-S.; Li, Y.; Wang, X.-R.; Mao, J.-F. Genetic evaluation of the breeding population of a valuable reforestation conifer Platycladus orientalis (Cupressaceae). Sci. Rep. 2016, 6, 34821. [CrossRef]

27. Woods, J. Methods for Estimating Gamete Contributions to Orchard Seed Crops and Vegetative Lots in British Columbia. BC Min. For. Range, Res. Br., Victoria, BC Tech. Rep. 025. 2005. Available online: http://www.for.gov.bc.ca/hfd/pubs/Docs/Tr/Tr025 .htm (accessed on 14 January 2017).

28. Ihaka, R.; Gentleman, R. R: A language for data analysis and graphics. J. Comp. Graph. Stat. 1996, 5, $299-314$.

29. International Business Machines Corporation. IBM SPSS Statistics for Windows; Version 24.0; International Business Machines Corporation: Armonk, NY, USA, 2012.

30. Chaisurisri, K.; El-Kassaby, Y.A. Estimation of clonal contribution to cone and seed crops in a Sitka spruce seed orchard. Ann. Sci. 1993, 50, 461-467. [CrossRef]

31. Griffin, A.R. Clonal variation in radiata pine seed orchards. I: Some flowering, cone and seed production traits. Aust. For. Res. 1983, 12, 295-302.

32. Choi, W.-Y.; Kang, K.-S.; Han, S.-U.; Hur, S.-D. Estimation of Heritabilities and Clonal Contribution Based on the Flowering Assessment in Two Clone Banks of Pinus koraiensis Sieb. et Zucc. In Breeding and Genetic Resources of Five-Needle Pines: Growth, Adaptability and Pest Resistance; Sniezko, R.A., Samman, S., Schlarbaum, S.E., Kriebel Howard, B., Eds.; USDA Forest Service: Medford, OR, USA, 2004; Volume 32, pp. 172-180.

33. Reynolds, S.; El-Kassaby, Y.A. Parental balance in Douglas-fir seed orchards-cone crop vs. seed crop. Silvae Genet. 1990, 39 , 40-42.

34. Bilir, N.; Prescher, F.; Ayan, S.; Lindgren, D. Growth characters and number of strobili in clonal seed orchards of Pinus sylvestris. Euphytica 2006, 152, 1-9. [CrossRef]

35. Nei, M. Analysis of gene diversity in subdivided populations. Proc. Natl. Acad. Sci. USA 1973, 70, 3321-3323. [CrossRef] [PubMed]

36. Lacy, R.C. Clarification of Genetic Terms and Their Use in the Management of Captive Populations; Wiley Subscription Services: New York, NY, USA, 1995; Volume 14, pp. 565-578. [CrossRef]

37. Lindgren, D.; Mullin, T.J. Relatedness and status number in seed orchard crops. Can. J. Res. 1998, 28, 276-283. [CrossRef]

38. Ertekin, M. Clone fertility and genetic diversity in a black pine seed orchard. Silvae Genet. 2010, 59, 145-150. [CrossRef]

39. Gömöry, D.; Bruchánik, R.; Paule, L. Effective population number estimation of three Scots pine (Pinus sylvestris L.) seed orchards based on an integrated assessment of flowering, floral phenology, and seed orchard design. For. Genet. 2000, 7, 65-75.

40. Kjær, E.D.; Wellendorf, H. Variation in flowering and reproductive success in a Danish Picea abies (Karst.) seed orchard. For. Genet. 1997, 4, 181-188.

41. Kang, K.-S.; Lindgren, D. Fertility variation among clones of Korean pine (Pinus koraiensis S. et Z.) and its implications on seed orchard management. For. Genet. 1999, 6, 191-200.

42. Ross, M. Sexual asymmetry in hermaphroditic plants. Trends Ecol. Evol. 1990, 5, 43-47. [CrossRef]

43. Burczyk, J.; Chalupka, W. Flowering and cone production variability and its effect on parental balance in a Scots pine clonal seed orchard. Ann. Sci. 1997, 54, 129-144. [CrossRef]

44. Schmidtling, R.C. Genetic variation in fruitfulness in a loblolly pine (Pinus taeda L.) seed orchard. Silvae Genet. 1983, $32,76-80$.

45. Bilir, N.; Kang, K.-S.; Zang, D.; Lindgren, D. Fertility variation and status number between a base population and a seed orchard of Pinus brutia. Silvae Genet. 2004, 53, 161-163. [CrossRef]

46. Kjær, E.D. Estimation of effective population number in a Picea abies (Karst.) seed orchard based on flower assessment. Scand. J. Res. 1996, 11, 111-121. [CrossRef]

47. Schultz, R.P. Stimulation of Flower and Seed Production in a Young Slash Pine Orchard, 1st ed.; US Department of Agriculture-Forest Service, Southeastern Forest Experiment: Asheville, NC, USA, 1971; p. 10.

48. Savolainen, O.; Kärkkäinen, K.; Harju, A.; Nikkanen, T.; Rusanen, M. Fertility variation in Pinus sylvestris: A test of sexual allocation theory. Am. J. Bot. 1993, 80, 1016-1020. [CrossRef]

49. Hannerz, M.; Aitken, S.; Ericsson, T.; Ying, C. Inheritance of strobili production and genetic correlation with growth in lodgepole pine. For. Genet. 2001, 8, 323-330. 
50. Kang, K.-S.; El-Kassaby, Y.A. Considerations of correlated fertility between genders on genetic diversity: The Pinus densiflora seed orchard as a model. Theor. Appl. Genet. 2002, 105, 1183-1189. [CrossRef]

51. Bilir, N.; Kang, K.-S.; Lindgren, D. Fertility variation in six populations of Brutian pine (Pinus brutia Ten.) over altitudinal ranges. Euphytica 2005, 141, 163-168. [CrossRef]

52. Kamalakannan, R.; Varghese, M.; Park, J.; Kwon, S.; Song, J.; Kang, K.-S. Fertility variation and its impact on effective population size in seed stands of Tamarindus indica and Azadirachta indica. Silvae Genet. 2015, 64, 91-99. [CrossRef]

53. Park, J.-M.; Kwon, S.-H.; Lee, H.-J.; Na, S.-J.; El-Kassaby, Y.A.; Kang, K.-S. Integrating fecundity variation and genetic relatedness in estimating the gene diversity of seed crops: Pinus koraiensis seed orchard as an example. Can. J. Res. 2017, 47, 366-370. [CrossRef]

54. Boydak, M. Regeneration of Lebanon cedar (Cedrus libani A. Rich.) on karstic lands in Turkey. Ecol. Manag. 2003, 178, 231-243. [CrossRef]

55. Yazici, N.; Bilir, N. Aspectual fertility variation and its effect on gene diversity of seeds in natural stands of Taurus cedar (Cedrus libani A. Rich.). Int. J. Genom. 2017, 2017, 2960624. [CrossRef]

56. Varghese, M.; Kamalakannan, R.; Nicodemus, A.; Lindgren, D. Fertility variation and its impact on seed crops in seed production areas and a natural stand of teak in southern India. Euphytica 2007, 160, 131-141. [CrossRef]

57. Kang, K.-S.; Lindgren, D.; Mullin, T.J. Fertility variation, genetic relatedness, and their impacts on gene diversity of seeds from a seed orchard of Pinus thunbergii. Silvae Genet. 2004, 53, 202-206. [CrossRef]

58. Hale, M.L.; Burg, T.M.; Steeves, T.E. Sampling for microsatellite-based population genetic studies: 25 to 30 individuals per population is enough to accurately estimate allele frequencies. PLoS ONE 2012, 7, e45170. [CrossRef]

59. Hoban, S.; Schlarbaum, S. Optimal sampling of seeds from plant populations for ex-situ conservation of genetic biodiversity, considering realistic population structure. Biol. Conserv. 2014, 177, 90-99. [CrossRef]

60. Volk, G.M.; Richards, C.M.; Reilley, A.A.; Henk, A.D.; Forsline, P.L.; Aldwinckle, H.S. Ex-situ conservation of vegetatively propagated species: Development of seed-based core collection for Malus sieversii. J. Am. Soc. Hort. Sci. 2005, 130, 203-210. [CrossRef]

61. Kang, K.-S.; Bila, A.; Harju, A.; Lindgren, D. Estimation of fertility variation in forest tree populations. Forestry 2003, 76, 329-344. [CrossRef]

62. Chaisurisri, K.; Edwards, D.; El-Kassaby, Y.A. Genetic control of seed size and germination in Sitka spruce. Silvae Genet. 1992, 41, 348-355.

63. El-Kassaby, Y.A.; Edwards, D.; Taylor, D. Genetic control of germination parameters in Douglas-fir and its importance for domestication. Silvae Genet. 1992, 41, 48-54. 